\title{
STUDIES IN MAN OF THE VOLUME OF THE RESPIRATORY DEAD SPACE AND THE COMPOSITION OF THE

\author{
ALVEOLAR GAS ${ }^{1}$
}

\author{
Br A. P. FISHMAN:
}

\begin{abstract}
(From the Department of Medicine, Columbia University. College of Physicians and Surgeons. and the Cardio-Pulmonary Laboratory of the litrst Medical and Chest Sericices

(Columbia Uniz'ersity Dizision), Bellew'ue Hospital, New' York, N. Y.)
\end{abstract}

(Submitted for publication July 14, 1953; accepted November 18, 1953)

Interest is currently focussed on the analysis of the factors influencing the exchange of oxygen and carbon dioxide between the blood and gas phases of the lung under a variety of experimental conditions. To this end, respiratory equations have been developed which include as unknowns either the volume of the respiratory dead space or the composition of alveolar gas. A new indirect method for determination of these two essential factors has been recently described by Pappenheimer, Fishman, and Borrero (1) and studied in anesthetized dogs and also in a few normal subjects. This method, hereafter referred to as the "iso-saturation method," makes possible the graphic solution of the Bohr formula for both the volume of the respiratory dead space and for the composition of alveolar gas; it entails the measurement of the composition of expired air over a wide range of tidal volumes, while respiratory gas tensions in the blood leaving the lungs are maintained constant during controlled hypoxemia.

The purpose of this paper is to extend the observations made on normal man with the iso-saturation method, and to explore its applicability to subjects with abnormal pulmonary function.

\section{Principle of the "Iso-Saturation Method"}

In order to facilitate the presentation of the results, the method, previously described in detail by Pappenheimer, Fishman, and Borrero (1), is briefly reviewed.

1 This investigation was supported (in part) by a research grant (PHS Grant H-833 (C)) from the National Heart Institute of the National Institutes of Health, Public Health Service, with additional support from the Life Insurance Medical Research Fund and the American Heart Association.

2 Established Investigator of the American Heart Association.
The expired breath may be considered to derive from two sources: 1. A respiratory dead space, where inspired gas (corrected to BTPS) has not exchanged oxygen and carbon dioxide with the blood and thus retains its identity ; and 2. an alveolar space, which contains inspired gas modified by exchanges of oxygen and carbon dioxide (at BTPS) with blood. The volume and composition of this alveolar component of the expired breath is determined by the respective volumes of the total ventilation and of the respiratory dead space, and by the relative contributions and ventilation-perfusion ratios of the gas exchanging areas of the lungs.

These considerations are the basis for the Bohr formula :

$$
V_{D_{x}}=\frac{\left(P_{E_{x}}-P_{A_{x}}\right)}{\left(P_{I_{x}}-P_{A_{x}}\right)} \cdot V T
$$

where

$\mathrm{VT}=$ ticlal volume

$V_{D_{x}}=$ volume containing respiratory dead space gas

$\mathrm{VA}_{\mathbf{x}}=$ volume containing alveolar gas $=\mathrm{VT}-\mathrm{VD}_{\mathrm{x}}$ $\mathrm{PI}_{\mathbf{x}}, \mathrm{PA}_{\mathbf{x}}, \mathrm{PE}_{\mathbf{x}}=$ the partial pressures of the gas in inspired, alveolar and expired gas, respectively; all volumes are expressed at body temperature, pressure, saturated with water vapor (BTPS),

and by substitution and rearrangement, using oxygen $\left(\mathrm{O}_{2}\right)$ as the test gas $x$

$$
\frac{\mathrm{VDO}_{\mathrm{O}_{2}}}{\mathrm{VT}}=\frac{\mathrm{PE}_{\mathrm{O}_{2}}-\mathrm{PA}_{\mathrm{O}_{2}}}{\mathrm{PI}_{\mathrm{O}_{2}}-\mathrm{PA}_{\mathrm{O}_{2}}}
$$

If the alveolar, as well as the inspired, gas mixture could be maintained constant despite variation in tidal volume, equation (2) then would be- 
come $(1,2)$

$$
\frac{\mathrm{VD}_{\mathrm{O}_{2}}}{\mathrm{VT}}=\mathrm{K} \cdot \mathrm{PE}_{\mathrm{O}_{2}}-\mathrm{K}_{1}
$$

where,

$$
\mathrm{K}=\frac{1}{\mathrm{PI}_{\mathrm{O}_{2}}-\mathrm{PAO}_{2}} \quad \text { and } \quad \mathrm{K}=\mathrm{K} \cdot \mathrm{PAO}_{2} .
$$

Similar considerations apply to the use of carbon dioxide $\left(\mathrm{CO}_{2}\right)$ as gas $x$.

The respiratory dead space. It is apparent that in equation (3), the volume of the dead space has become a function of the tidal volume and expired gas composition. It was indicated in the original report (1) that graphic solution of the Bohr formula with constant inspired and alveolar gas permitted evaluation of two experimental possibilities :

1. $\mathrm{VDO}_{2}$ varies proportionally as $\mathrm{VT}$ so that $\frac{\mathrm{VDO}_{2}}{\mathrm{VT}}$ is constant and $\therefore \mathrm{PEO}_{2}$ remains constant as VT varies.

2. $\mathrm{VDO}_{2}$ is constant and independent of $\mathrm{VT}$, so that $\mathrm{PEO}_{2}$ varies linearly as $\frac{1}{\mathrm{VT}}$.
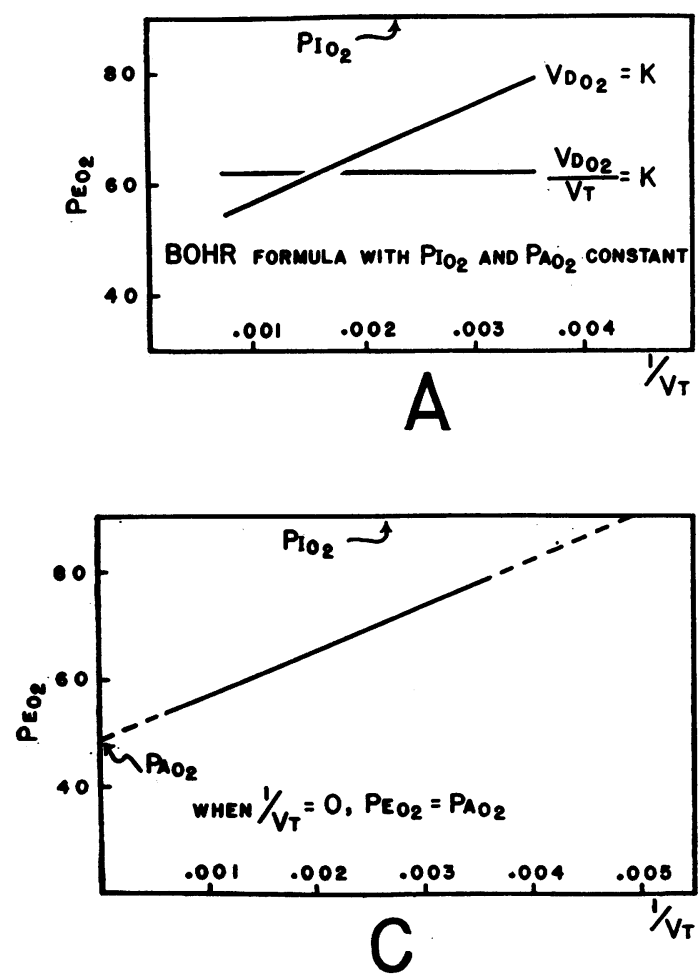

The two possibilities are illustrated in Figure 1A. These possibilities were experimentally tested in the previous study (1) and it was shown, under the conditions of the experiments, that $\mathrm{VDO}_{2}=$ $\mathrm{K}$. Consequently, progressive decrease in tidal volume until $\mathrm{VT}=\mathrm{VD}_{\mathbf{x}}$ (where $\mathrm{x}$ is either oxygen or carbon dioxide) makes $\mathrm{PE}_{\mathbf{x}}=\mathrm{PI}_{\mathbf{x}}$, and numerical values for $V_{D_{x}}$ may be obtained by extrapolation. This is illustrated for $\mathrm{VDO}_{2}$ in Figure $1 \mathrm{~B}$, and compared with $\mathrm{VDCO}_{2}$ in Figure 1D.

Alveolar gas tension. When $\frac{1}{\mathrm{VT}_{\mathrm{T}}}=0, \mathrm{P}_{\mathrm{A}_{\mathbf{x}}}=$ $\mathrm{PE}_{\mathbf{x}}$ and a numerical solution for $\mathrm{PA}_{\mathbf{x}}$ can be obtained by extrapolation. Figure $1 \mathrm{C}$ illustrates the use of this method to obtain $\mathrm{PAO}_{2}$ and Figure 1D includes the determination of $\mathrm{PACO}_{2}$.

The application of the iso-saturation method to the solution of equation (3) depends on the use of arterial blood as an index to constant mean alveolar gas composition. Earlier experiments (1) with inspired gas mixtures low in oxygen content, have demonstrated that with controlled respiratory frequency and over a wide range of tidal volume, a stable degree of arterial hypoxemia
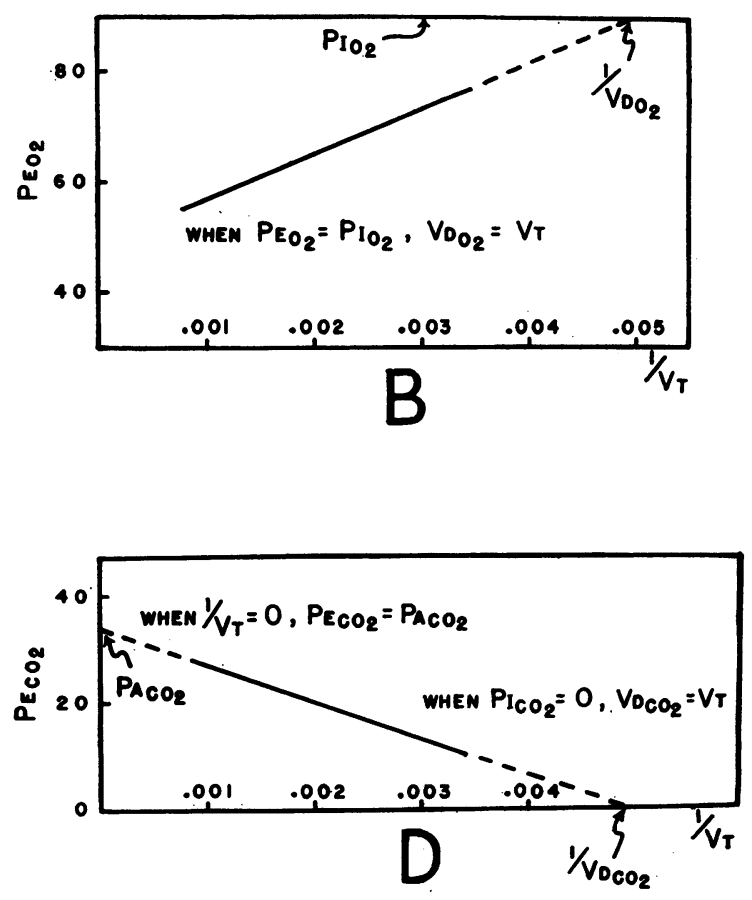

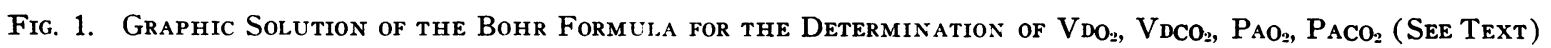


can be achieved, employing an oximeter as a nullpoint indicator of arterial per cent $\mathrm{HbO}_{2}$ saturation. Furthermore, under these conditions, the linear alignment of the experimental points relating the composition of expired air to the reciprocal of the tidal volume, implies constancy of mean alveolar gas composition, and, therefore, of the A-a gradient.

\section{METHODS}

All experiments were done with the subject comfortably seated. In each experiment, successive points were obtained, at different respiratory frequencies. Frequency of respiration ranged from 8 to 88 per minute and was fixed for each experimental point by synchronization of breathing with a metronome; the depth of ventilation was regulated voluntarily so to maintain a constant per cent $\mathrm{HbO}_{2}$ in arterial blood as controlled by oximetry, thus insuring minimal fluctuations in $\mathrm{PaO}_{2}$.

In some instances, a mild degree of exercise was used in order to achieve larger tidal volumes. This was done by means of a stationary bicycle ergometer, allowing sufficient time (approximately 15 minutes) for a steady state of respiration and of circulation to be reached.

A Millikan oximeter (single channel with compensated circuit, C.M.R. Model 13) was used throughout these experiments as a nullpoint instrument. This device permitted the subject to adjust his ventilation so as to return to the same per cent $\mathrm{HbO}_{2}$ mark on the galvanometer dial during successive experiments. The exact saturation corresponding to this mark was determined by arterial blood' sampling and determination of its oxygen content and oxygen capacity with the Van Slyke-Neill apparatus.

In subjects free of pulmonary disease the oximeter scale was set at 100 after approximately 5 minutes of breathing 100 per cent oxygen, whereas in patients with pulmonary disease, the per cent $\mathrm{HbO}_{2}$ in arterial blood was determined directly by gas analysis, and the oximeter scale set accordingly. The instrument was checked for drift or instability at the end of each determination, and a deviation of greater than 2 per cent from the initial "ear thickness" or "saturation" readings caused the experiment to be discarded. An appropriate inspired mixture of oxygen in nitrogen was chosen in order to reduce the per cent $\mathrm{HbO}_{2}$ saturation in arterial blood to a range of 70 to 80 per cent. Whereas a 10 to 12 per cent oxygen mixture was needed to accomplish this comfortably in normal subjects, higher inspired oxygen mixtures were required in one of the subjects with pulmonary disease. The inspired mixture was made available through a demand valve as the subject breathed in time with a metronome, adjusting his tidal volume to reach the indicated saturation. Approximately 10 to 15 minutes after stabilization at the indicated galvanometer reading, three washouts of the spirometer with expired gas were completed, and a twominute sample was collected for measurement of tidal volume and analysis. Repeated measurements of ventila- tion, oxygen intake, and respiratory exchange ratio obtained between 10 to 15 minutes after stabilization of the galvanometer reading, suggested that a steady state of ventilation, circulation, and gas exchange had been reached.

Arterial blood samples were drawn during the gas collection period through an indwelling brachial arterial needle, previously placed following novocaine anesthesia. $\mathrm{PaO}_{2}$ and $\mathrm{PaCO}_{2}$ were determined directly and indirectly, in duplicate, according to methods previously described $(3,4)$. The results by both methods were required to check within $2 \mathrm{~mm}$. $\mathrm{Hg}$, for inclusion in the study. The partial pressures of oxygen and carbon dioxide in expired and inspired gases were calculated from the results of gas analysis using the $0.5 \mathrm{ml}$. micro-Scholander analyzer. With data thus obtained; the A-a gradients and oxygen diffusing capacity (DLOz) of the lungs were calculated. For the latter calculation, made only in normal subjects, (a) the oxygen uptake figure was the average of multiple measurements; (b) the mean oxygen pressure gradient between the alveolar gas and the capillary blood was determined by a modification of Bohr's graphic integration method previously described (5), assuming that the mixed venous-capillary blood per cent $\mathrm{HbO}_{2}$ difference was 25 per cent and that, at the level of hypoxia employed, the venous admixture component of the A-a gradient was negligible. Obviously these assumptions can only apply to the normal subject.

\section{Subjects for study}

Eight normal subjects and three patients with abnormal pulmonary function were investigated. The pertinent vital statistics appear in Table I. The three patients selected had not on previous studies shown significant physiologic variation from day to day. They represent three distinct types of pulmonary dysfunction: 1 . Nonobstructive emphysema; 2 . overdistension of a normal lung following pneumonectomy; and 3. alveolar-capillary

TABLE I

Vital statistics of eleven subjects studied

\begin{tabular}{|c|c|c|c|c|c|c|}
\hline Subject & Age & Sex & Height & $\begin{array}{l}\text { Body } \\
\text { surface } \\
\text { area }\end{array}$ & $\begin{array}{c}\text { Vital } \\
\text { capacity }\end{array}$ & Diagnosis \\
\hline & & & $\mathrm{cm}$. & $m^{2}$ & $m l$. & \\
\hline A.P.F. & 33 & $\mathrm{~m}$ & 183 & 2.08 & 5130 & Normal \\
\hline P.S. & 30 & $\mathrm{~m}$ & 185 & 2.20 & 4740 & Normal \\
\hline W. B. & 32 & $\mathrm{~m}$ & 180 & 1.99 & 5560 & Normal \\
\hline S. R. & 38 & $\mathrm{~m}$ & 174 & 1.84 & 4450 & Normal \\
\hline M. B. & 29 & $\mathrm{~m}$ & 180 & 2.05 & 5400 & Normal \\
\hline L. D. & 28 & $\mathrm{f}$ & 168 & 1.63 & 4300 & Normal \\
\hline & 36 & $\mathrm{~m}$ & 182 & 2.00 & 6560 & Normal \\
\hline R. Mc. & 30 & $\mathrm{~m}$ & 175 & 1.90 & 4860 & Normal \\
\hline G. W. & 67 & $\mathbf{m}$ & 169 & 1.70 & 3040 & $\begin{array}{l}\text { Non-obstructive } \\
\text { pulmonary } \\
\text { emphysema }\end{array}$ \\
\hline G. B. & 49 & $\mathrm{~m}$ & 180 & 1.84 & 2315 & $\begin{array}{l}1 \text { month post right } \\
\text { pneumonectomy }\end{array}$ \\
\hline E. H. & 19 & $\mathrm{~m}$ & 175 & 1.68 & 2860 & $\begin{array}{l}\text { Diffuse pulmonary } \\
\text { granulomatosis }\end{array}$ \\
\hline
\end{tabular}


TABLE II

Summary of physiologic measurements in the three patients with various types of pulmonary insufficiency

\begin{tabular}{|c|c|c|c|c|}
\hline Measurement & Normal & G. W. & G. B. & E. H. \\
\hline \multicolumn{5}{|l|}{$\begin{array}{l}\text { Lung volumes in per cent } \\
\text { of predicted value }\end{array}$} \\
\hline Vital capacity & 100 & 73 & $105^{*}$ & 55 \\
\hline Total capacity & 100 & 113 & $104^{*}$ & 61 \\
\hline Residual air & 100 & 254 & $145^{*}$ & 8.3 \\
\hline$\frac{\text { Residual air }}{\text { Total capacity }} \times 100$ & 25 & 55 & 3.3 & 27 \\
\hline $\begin{array}{l}\text { Maximum breathing } \\
\text { capacity in per cent } \\
\text { of predicted value }\end{array}$ & 100 & 71 & 42 & 100 \\
\hline $\begin{array}{l}\text { Alveolar } \mathrm{N}_{2} \text { per cent } \\
\text { after } 7 \text { min. pure } \\
\text { oxygen breathing }\end{array}$ & 2.5 & 2.17 & 1.08 & 1.58 \\
\hline \multicolumn{5}{|l|}{$\begin{array}{l}\text { Ventilation in L./min./ } \\
\text { sq.m.b.s. } \dagger\end{array}$} \\
\hline Rest & 3.1 & 5.46 & $-\cdot$ & 6.50 \\
\hline $1 \mathrm{~min}$. standard exercise & 10.7 & 12.10 & & 19.70 \\
\hline \multicolumn{5}{|l|}{ Arterial blood $\% \mathrm{HbO}_{2} \ddagger$} \\
\hline $\begin{array}{l}\text { Rest } \\
1 \text { min. recovery, post- }\end{array}$ & 96 & 95 & 96 & 92 \\
\hline exercise & 96 & 95 & - & 75 \\
\hline \multicolumn{5}{|l|}{ Arterial blood } \\
\hline at rest, in $\mathrm{mm}$ & 38 & +2 & - & 39 \\
\hline
\end{tabular}

* Compared to predicted values for normal lung. + Sq.m.b.s. = square meter of body surface area. $\ddagger$ While breathing 21 per cent oxygen.

block associated with diffuse granulomatosis of the lung. The results of pulmonary function studies on each of the three patients are presented in Table II.

\section{RESULTS}

The results in the eight normal subjects and in the three patients will be considered separately. All measurements made at rest and data calculated therefrom, are summarized in Table III, including the volume of the respiratory dead space and the composition of alveolar gas obtained by extrapolation.

\section{Normal Subjects}

The results confirm those previously reported (1) and are illustrated for two subjects in Figures 2,3 , and 4 . These figures are representative of those obtained in all the subjects, and demonstrate that the experimental points cluster around a sloping straight line with a minimum of scatter, and therefore make possible the extrapolations which are necessary to define the volume of the respiratory dead space $\left(\mathrm{VDO}_{2}\right.$ and $\left.\mathrm{VDCO}_{2}\right)$ and the alveolar gas composition $\left(\mathrm{PAO}_{2}\right)$ and $\left(\mathrm{PACO}_{2}\right)$.

The points obtained during mild exercise in two subjects are indicated by separate symbols in the figures and fall on the same straight line as those obtained at rest. In a few experiments performed during more strenuous exercise, the points fell above the line. They were invariably associated with a higher respiratory exchange ratio $(\mathrm{RE})$ than recorded in Table III. Since either a change in A-a gradient, or failure to achieve the steady state, may account for these observations, and since a fixed A-a gradient and maintenance of a steady state are prerequisite for the application of the method, these few points are not illustrated in the figures.

\section{Volume of the respiratory dead space}

The main findings concerning the volume of the respiratory dead space were as follows: (a) The sloping straight line indicates (equation (3), Figures 1 and 2$)$, that $V_{D}$ is constant despite variation in VT; (b) the addition of a measured external dead space increases the calculated $V_{D}$ by an amount equivalent to the water capacity of the added tube. As seen in Figure 4. $\mathrm{V}_{\mathrm{no}}$, and $V_{\text {DCO.2 }}$ increase by $156 \mathrm{ml}$., and $150 \mathrm{ml}$., respectively, after addition of an external $V_{D}$ of $150 \mathrm{ml}$. As seen in the same figure, the application of a tight abdominal binder to change the midposition of the chest, did not alter significantly either the $V{ } o_{2}$ or the VDCO.2; similar observations were made in subject P. S.; (c) the VD is fixed and is not influenced by variations in the composition of the low oxygen mixture which is used to maintain iso-saturation (Figure 3): when the same type of experiments are done by a trained subject, without anoxia or oximeter control, using room air as the inspired gas mixture, and voluntary adjustment of tidal volume to achieve comfortable ventilation at a given frequency, a considerable scatter of experimental points is observed (Figure 5). This scatter was anticipated since the subject maintained his arterial per cent $\mathrm{HbO}_{2}$ in the upper, flat, part of the oxyhemoglobin dissociation curve, where slight changes in per cent $\mathrm{HbO}_{2}$ may be associated with marked changes in $\mathrm{PaO}_{2}$; (e) during all the experimental variations described above. $V_{\text {Do.2 }}$ and $\mathrm{VDCO}$, remained approximately equal. 
RESPIRATORY DEAD SPACE AND ALVEOLAR GAS COMPOSITION

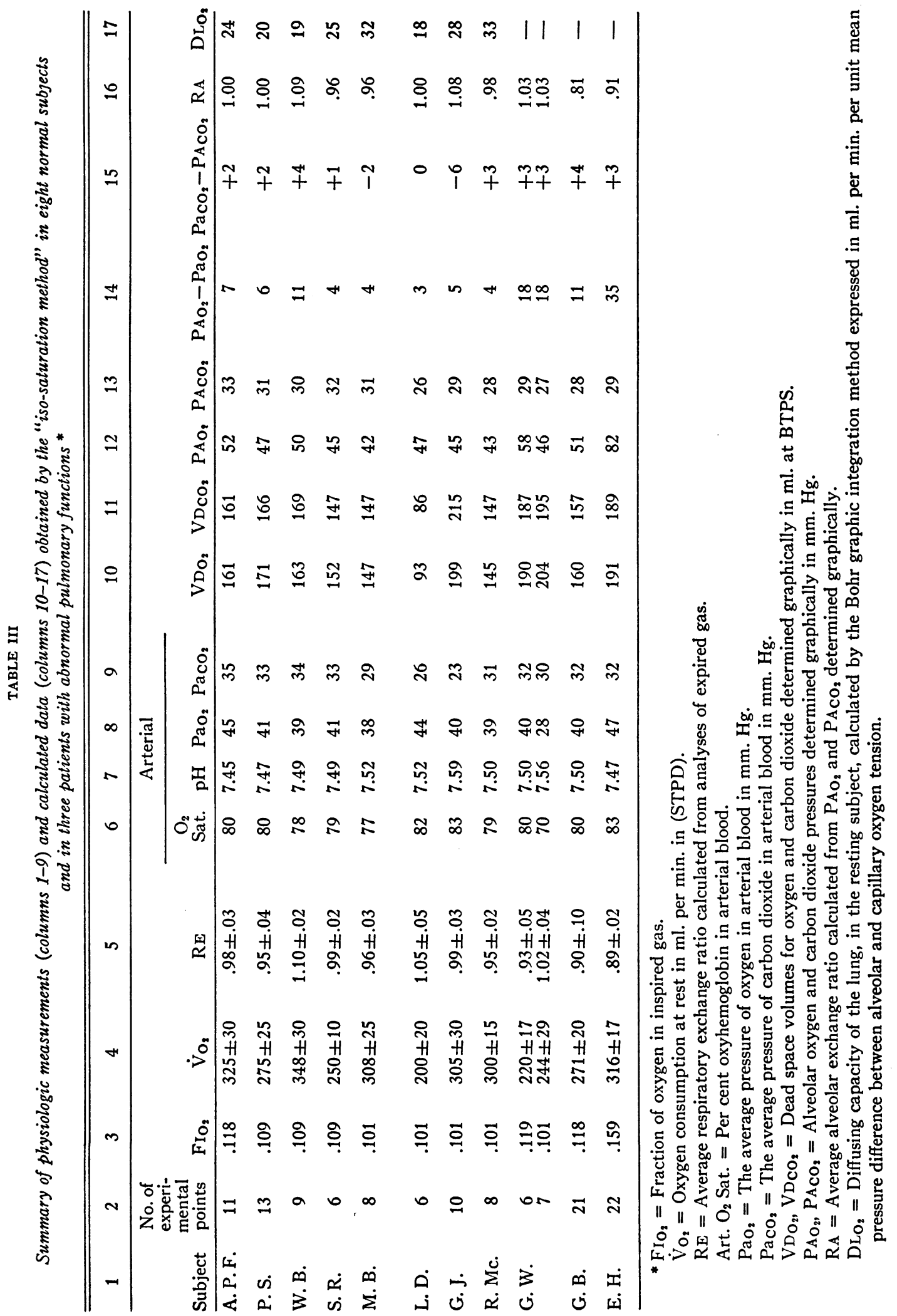




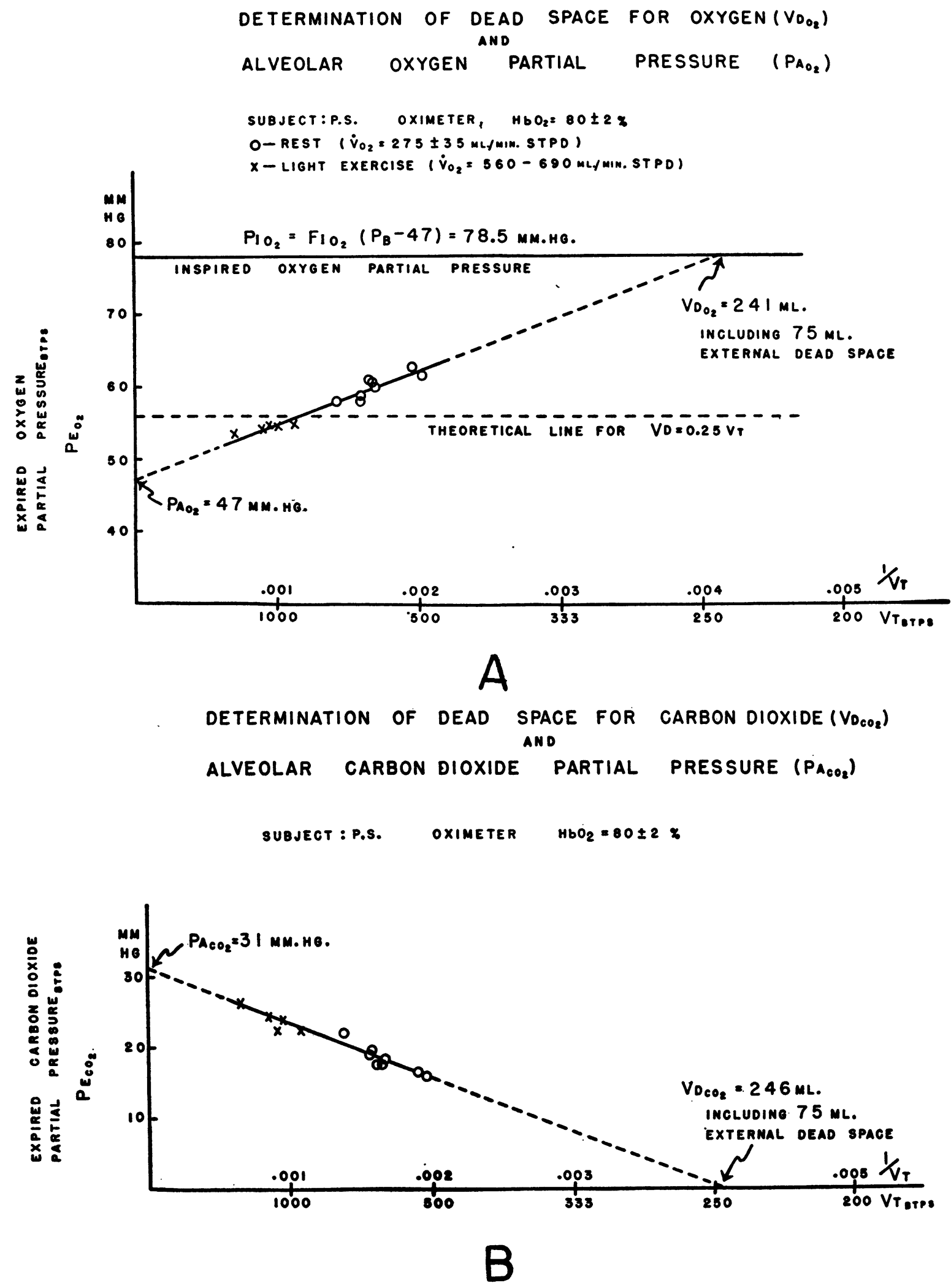

Figs. 2 A and B. Illustrations of the Application of the Iso-saturation Method in a Normal Sudject Note that the experimental points fall on 2 sloping straight line. 


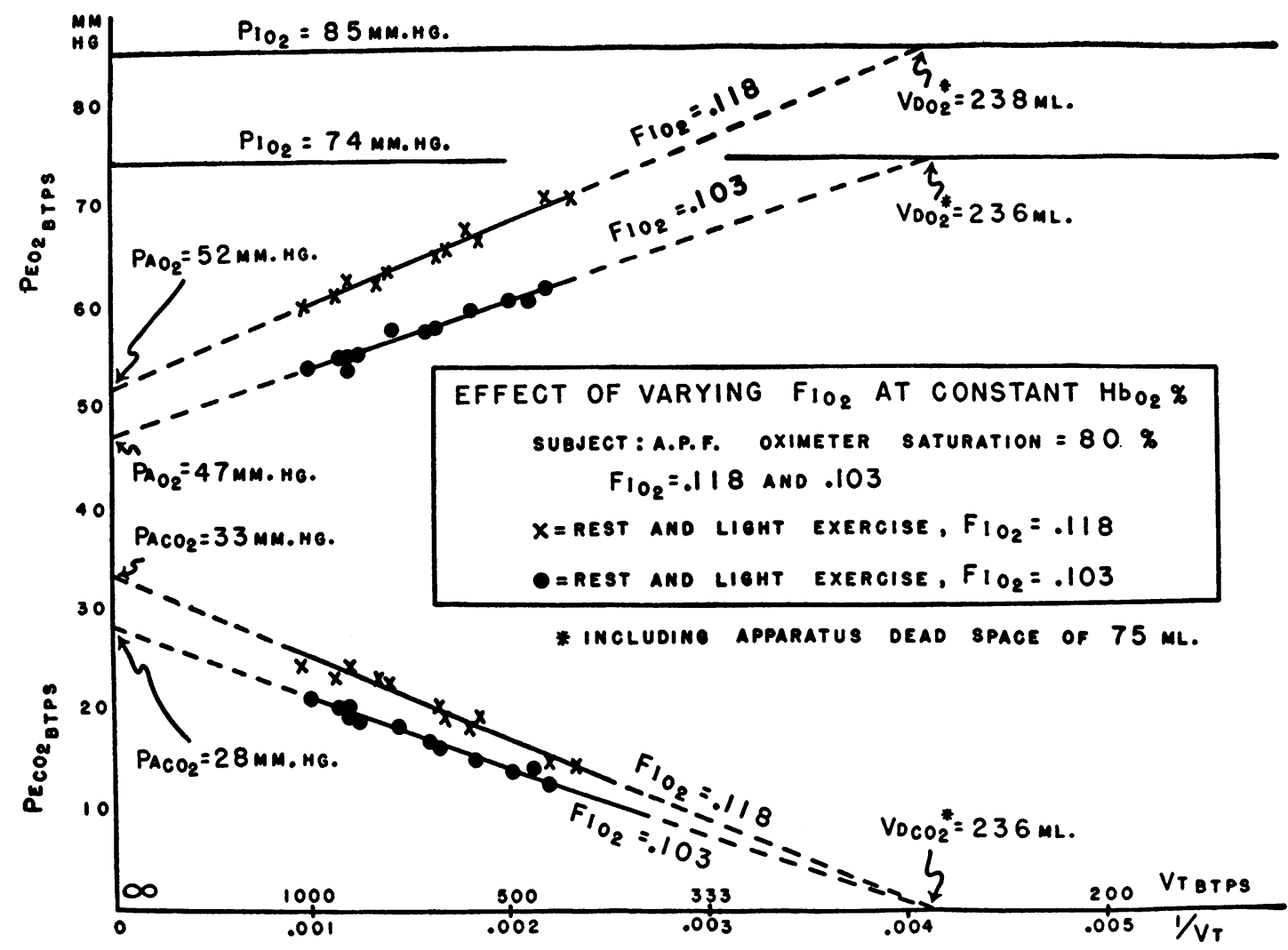

Fig. 3. Application of the Iso-saturation Method in a Normal Subject-Effect of Varying Inspired Gas Mixture

Note that $\mathrm{VDO}_{2}$ and $\mathrm{VDCO}_{2}$ remain constant and equal, and that $\mathrm{PAO}_{2}$ and $\mathrm{PACO}_{2}$ vary.

\section{Alveolar gas composition}

The extrapolated values of $\mathrm{PAO}_{2}$ and $\mathrm{PACO}_{2}$ obtained under the conditions of these experiments ranged, respectively, from 42 to $55 \mathrm{~mm}$. $\mathrm{Hg}$, and from 26 to $33 \mathrm{~mm}$. $\mathrm{Hg}$. These variations are in part related to the different degrees of hyperventilation required to maintain approximately the same level of per cent $\mathrm{HbO}_{2}$ saturation. This effect is well illustrated in Figure 3, where two different inspired gas mixtures were used to maintain the same per cent $\mathrm{HbO}_{2}$. It can also be seen in Table III, that the exchange ratio of alveolar gas (RA) obtained by extrapolation corresponds closely to the expired gas exchange ratio $(R E)$.

\section{Alveolar-arterial $\mathrm{O}_{2}$ and $\mathrm{CO}_{2}$ gradients and oxygen diffusing capacity of the lungs}

The values for alveolar tensions $\left(\mathrm{PAO}_{2}\right.$ and $\mathrm{PACO}_{2}$ ) obtained by extrapolation were used in conjunction with blood gas tensions $\left(\mathrm{PaO}_{2}\right.$ and
$\mathrm{PaCO}_{2}$ ) obtained by analyses of the arterial blood, to determine in normal subjects the A-a gradient for oxygen and $\mathrm{CO}_{2}$, and to calculate the oxygen diffusing capacity of the lung $\left(\mathrm{DLO}_{2}\right)$. As seen in Table III : (a) the $\mathrm{O}_{2} \mathrm{~A}$-a gradient ranged between 3 and $11 \mathrm{~mm} . \mathrm{Hg}$, with an average of $6 \mathrm{~mm} . \mathrm{Hg}$; (b) the $\mathrm{CO}_{2} \mathrm{~A}$-a gradient varied from -6 to +4 $\mathrm{mm} . \mathrm{Hg}$, with an average of $0.5 \mathrm{~mm} . \mathrm{Hg}$; and (c) the $\mathrm{DLO}_{2}$ at rest ranged from 18 to 33 with an average of $22 \mathrm{ml}$. per min. per $\mathrm{mm}$. $\mathrm{Hg}$.

\section{Patients with Pulmonary Dysfunction}

The results in these three patients demonstrate that the experimental points fall, as in the normal subjects, along a sloping straight line with a minimum of scatter. This is illustrated in Figures 6 and 7.

\section{Volume of respiratory dead space}

In the three patients, $\mathrm{VDO}_{2}$ and $\mathrm{VDCO}_{2}$ were equal, and not influenced by mild exercise, by vari- 
ation in the arterial per cent $\mathrm{HbO}_{2}$, or by addition of an external dead space. Two subjects, G. W. and E. H., of relatively small size (Table I) had relatively large dead space volumes. The third subject, G. B., with a (overdistended) single lung, had a VD equal to $160 \mathrm{ml}$.

\section{Alveolar gas composition}

In the patient G. W., with non-obstructive emphysema, and in G. B., with a single, overdistended lung, the $\mathrm{PAO}_{2}$ and $\mathrm{PACO}_{2}$ were not significantly different from those observed in normals with similar oxygen mixtures. In E. H., with diffuse granulomatosis of the lung, the composition of the gas mixture required to maintain 80 per cent saturation was higher, and therefore, comparison of the alveolar $\mathrm{PAO}_{2}$ with the normal subject is not possible.

\section{Alveolar-arterial $\mathrm{O}_{2}$ pressure gradient}

The A-a gradients in patient G. W., determined in two distinct series of experiments at two levels of arterial per cent $\mathrm{HbO}_{2}$ saturation ( 80 per cent and 70 per cent, respectively) were $18 \mathrm{~mm}$. $\mathrm{Hg}$ (Table III). This is a much larger figure than seen in any of the normal subjects.

In the patient E. H., with diffuse granulomatosis, the A-a gradient reached the high value of 35 $\mathrm{mm} . \mathrm{Hg}$. It is of particular interest that in the same subject, using the Riley-Cournand method of analysis and a 16 per cent oxygen mixture which resulted in a similar lowering of the arterial per cent $\mathrm{HbO}_{2}$, a value of $29 \mathrm{~mm}$. $\mathrm{Hg}$ was obtained. In subject $G$. B. with one remaining lung, the $A-a$ gradient was within the normal range.

The oxygen diffusing capacity was not calculated in the two subjects with the large A-a gradi-

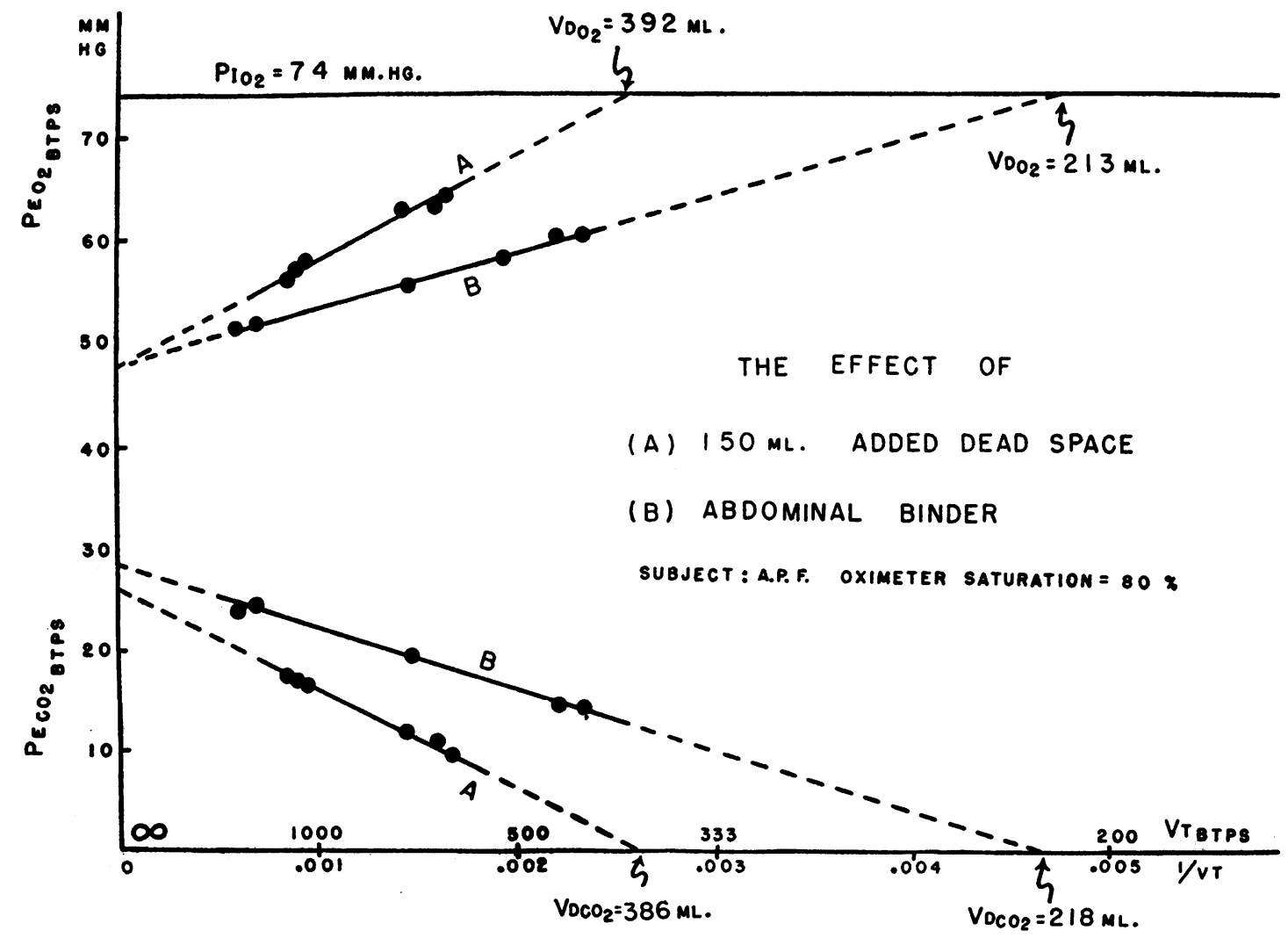

Fig. 4. Application of the Iso-saturation Method in a Normal Subject

Note that (a) addition of a measured additional dead space causes a corresponding increase in the measured VD (see Figure 3), and (b) that change in the mid-position of the lung by an abdominal binder causes only a slight decrease in VD. 


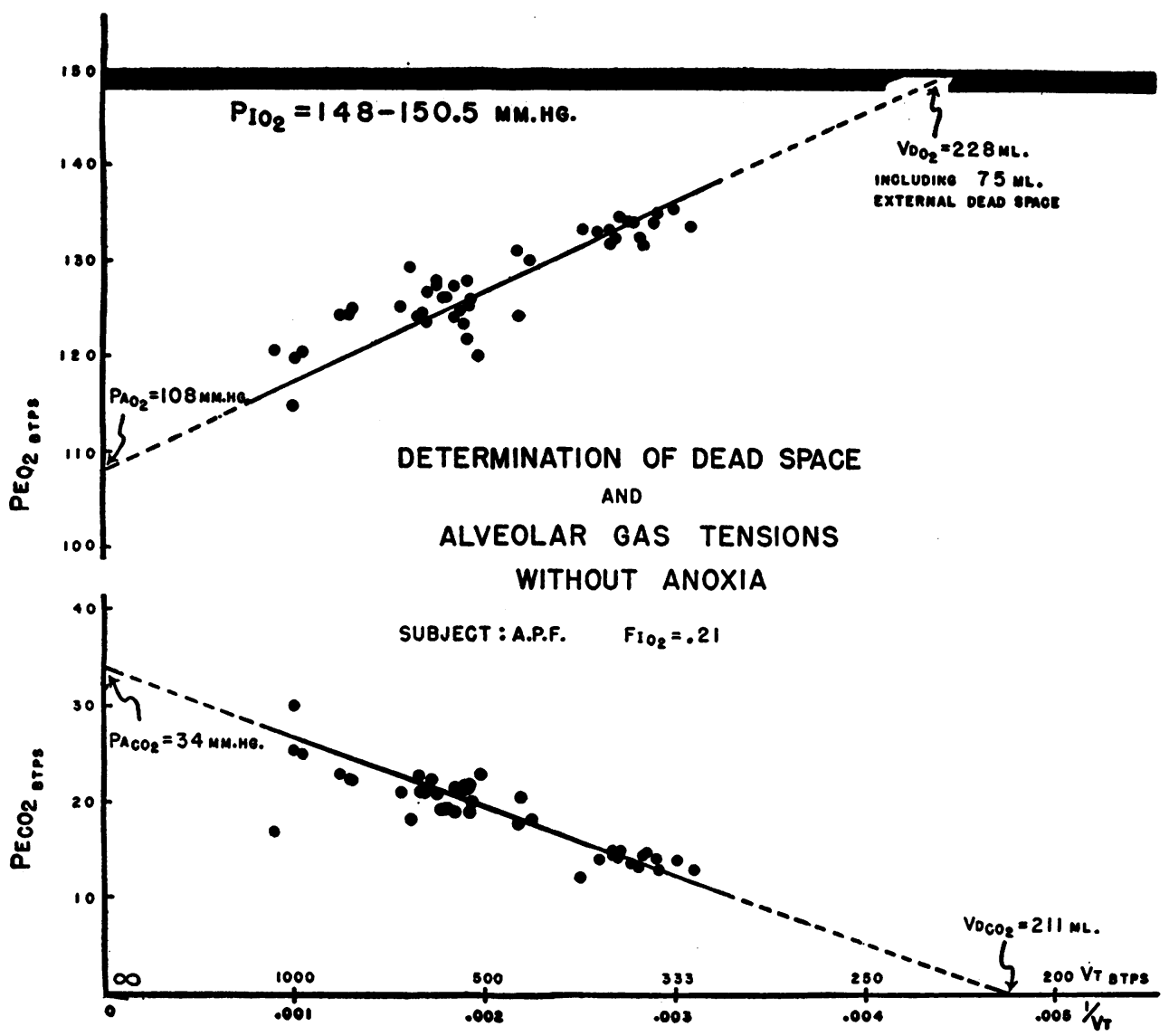

Fig. 5. Application of the Iso-saturation Method in a Normal Subject

Note that without anoxia there is a considerable scatter of the experimental points.

ents, since in the presence of pulmonary disease, despite significant arterial per cent $\mathrm{HbO}_{2}$ unsaturation, the specific contribution of venous admixture to the A-a gradient cannot be ascertained. In the subject with one single lung, it was calculated to be 13 , a figure below the range observed in normals.

\section{DISCUSSION}

\section{Respiratory dead space}

The results described above confirm those of the earlier study with the iso-saturation method (1) and indicate that the volume of the respiratory dead space (VD) remains constant despite wide variation in tidal volume (VT) and that this constancy is maintained during a wide variety of experimental conditions, including change in the composition of inspired gas and the addition of external dead space. The data furthermore indicate that $\mathrm{VDO}_{2}$ is equal to $\mathrm{VDCO}_{2}$, and that, therefore, in the steady state, $R A=R E$.

By this method, the VD in the normal male subjects averaged $164 \mathrm{ml}$., with a range from $145 \mathrm{ml}$. to $215 \mathrm{ml}$., and in the normal female subject studied (L. D.) was $90 \mathrm{ml}$. These values correspond well with those recently described by other investigators using different methods. Thus, Fowler (6) used continuous, rapid analysis of the expired breath for nitrogen to identify completion of dead space wash-out and calculated an average "physiological" VD of $156 \mathrm{ml}$. in males and $104 \mathrm{ml}$. in females. DuBois, Fowler, Soffer, and Fenn (7) determined "sequential" alveolar carbon dioxide values by continuous analysis of the expired breath and obtained by substitution in the Bohr formula an average "physiological" VD of $177 \mathrm{ml}$. in normal males. Hatch, Cook, and Palm (8) ap- 

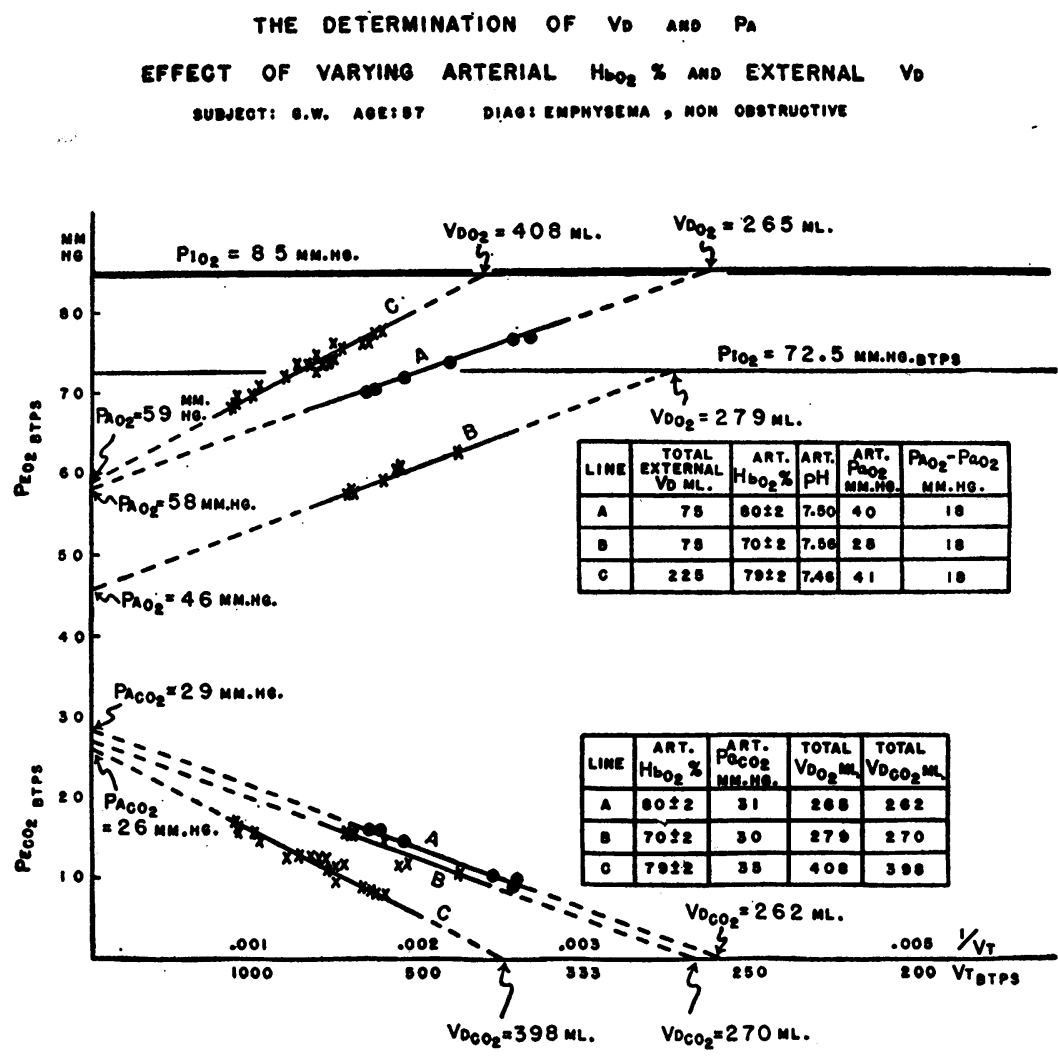

Fig. 6. Application of the Iso-saturation Method in a Patient with Non-obstructive Emphysema under a Variety of Experimental Conditions, Including Variations in Degree of ANoxia and Addition of an External Dead Space

Note that alignment of experimental points and the results confirm observations made in normal subjects.

plied fractional analysis of the expired breath to an experimental method somewhat similar in principle to the iso-saturation method, and concluded that the average "anatomic" VD in normal male subjects was $130 \mathrm{ml}$.

Despite the designation "anatomic" or "physiological," these volumes for VD are closely similar. This is readily understood from a brief consideration of the Bohr formula, where VD emerges as a function of the value and the method used for PA. In normal resting subjects, a variety of methods yield the same $\mathrm{PA}_{\mathrm{A}}$; in the presence of pulmonary disease, or during deviation from the resting state, discrepancies may be anticipated, the degree of difference depending on the method of sampling. Thus, the iso-saturation method, based on graphic solution of the Bohr formula, defines a well-ventilated, non-perfused space where no measurable gas exchange occurs, and in which the inspired gas mixture retains its initial composition. In normal subjects this space must closely approximate the volume of the conducting airway, the anatomic VD.

In contrast, the $\mathrm{VD}$ determined by substituting $\mathrm{PaCO}_{2}$ for $\mathrm{PACO}_{2}$ in the alveolar gas equation, as done in the Riley-Cournand method of analysis of ventilation-perfusion relationships, (4) includes not only this space, defined by its inspired gas composition rather than anatomic boundary, but also a fraction of the alveolar volume which is well ventilated, but poorly perfused..$^{8}$ In our series of

8 This latter volume may be schematically represented by subdividing the total alveolar volume ( $V_{A T}$ ) of known composition $\left(\mathrm{P}_{\mathrm{A}_{\mathbf{x}}}\right)$ into two virtual volumes with the following arbitrary composition: virtual volume $1\left(V_{A_{1}}\right)$, containing "effective" alveolar gas $\left(P_{A_{x}}^{e}\right)(5)$ and vir- 


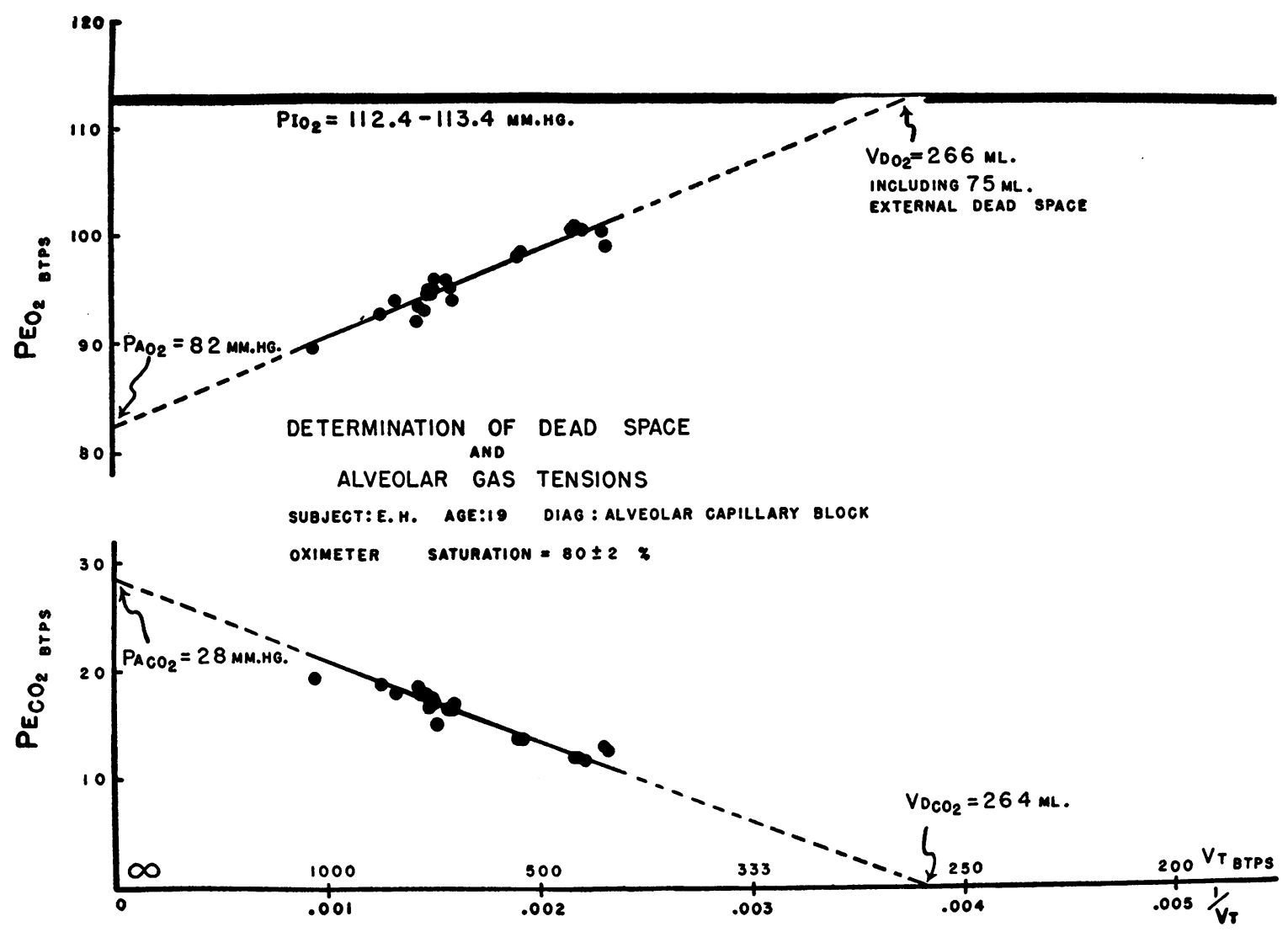

Fig. 7. Application of the Iso-saturation Method in a Patient with Diffuse Granulomatosis of the Lungs

seven normal male subjects, the mean and range of variation of VD measured (a) by the iso-saturation method and (b) by substituting $\mathrm{PaCO}_{2}$ for

tual volume $2\left(V_{A_{2}}\right)$ with the same composition as inspired gas $\left(\mathrm{PI}_{\mathbf{x}}\right)$. Therefore, $\mathrm{V}_{\mathbf{A}_{\mathbf{T}}} \cdot \mathrm{P}_{\mathbf{A}_{\mathbf{x}}}=\mathrm{V}_{\mathbf{A}_{\mathbf{1}}} \cdot \mathrm{P}_{\mathbf{A}_{\mathbf{x}}}^{\mathbf{e}}+$ $\mathrm{VA}_{\mathbf{2}} \cdot \mathrm{PI}_{\mathbf{x}}$. The "physiological" dead space of Riley and Cournand is the sum of the non-gas exchanging volume (defined by the iso-saturation method) + virtual volume $2\left(V_{A_{2}}\right)$. In normal subjects, $V_{A_{2}}$ is very small, since there is little inhomogeneity of ventilation and perfusion.

In short, any method for determination of $\mathrm{VD}$ based on the addition of a detector gas to the inspired gas mixture, measures a space closely approximating the anatomic $V D$, plus an additional volume related to diffusion at the interface between anatomic VD and alveolar gas; the isosaturation method measures a similar volume. On the other hand, any method using a tracer gas which has undergone gas exchange, such as carbon dioxide, defines a VD which is physiologically ineffective, and is influenced by the dynamics of alveolar ventilation and/or variations in ventilation-perfusion relationships.

This view has been previously expressed by GrosseBrockhoff and Schoedel. Grosse-Brockhoff, F., and Schoedel, W., Der effective schädliche Raum. Pflügers Arch., 1937, 238, 213.
$\mathrm{PACO}_{2}$ in the Bohr equation, were almost identical. By the first method, the mean VD equals $164 \mathrm{ml}$., with the range from 145 to $215 \mathrm{ml}$., as compared to VD equal to $174 \mathrm{ml}$, with a range from 140 to $208 \mathrm{ml}$. by the second method. The VD was also calculated by the two methods in the three patients, since it was anticipated that differences might appear. However, in the patient with nonobstructive emphysema, and in the patient with a single distended lung, the VD were almost identical by both methods. In only one patient, with considerable impairment of gas exchange due to widespread granulomatosis of the lungs, was the discrepancy very significant. In this subject, VD by the iso-saturation method measured $189 \mathrm{ml}$., and by the other method, $277 \mathrm{ml}$.

\section{The alveolar-arterial oxygen pressure gradient and diffusion constant of the lung}

The alveolar gas tension obtained by the isosaturation method represents the alveolar component of expired gas (4). It differs from "ef- 
fective" alveolar gas tension which is based on the use of arterial blood, because of contributions from well-ventilated, poorly perfused alveoli. In normal subjects, where there is little inhomogeneity of ventilation and perfusion, the differences between "effective" alveolar gas and the alveolar component of expired gas fall within the errors of the methods used for their determination.

The studies made by the iso-saturation method were all performed during anoxia. Consequently the calculated A-a gradient is a measure, in normals, of the failure of pulmonary capillary blood to reach equilibrium with alveolar oxygen tension. This gradient which averaged $6 \mathrm{~mm}$. $\mathrm{Hg}$ with a range from 3 to $11 \mathrm{~mm}$. $\mathrm{Hg}$ in normal subjects, compares well with the A-a gradient determined in normal subjects during anoxia by Lilienthal, Riley, Proemmel, and Franke (9).

The diffusion coefficient of the lung was calculated in the normal subjects using the A-a gradients and the Riley modification of the Bohr integration technique. The results were again similar to those calculated independently by the RileyCournand method of analysis. Similar calculations in the patients with pulmonary disease could not be done since no assumption as to the negligible effect of venous admixture on the A-a gradient during anoxia can be made.

\section{Clinical value of the iso-saturation method}

This method makes possible the determination of the volume of the respiratory dead (non-gas exchanging) space, the composition of alveolar gas and the A-a oxygen and carbon dioxide gradients during hypoxia, and the diffusion coefficient of the lungs in normal subjects and in patients with pulmonary dysfunction. However, the large number of experimental points needed for each determination, plus the high degree of cooperation required of the subject, and finally, the necessity of maintaining a steady state of circulation and respiration, limit the clinical utility of this method.

\section{SUM MARY}

1. The graphic solution of the Bohr formula according to the method described by Pappenheimer, Fishman, and Borrero (1) has been applied to the determination of the volume of the respiratory dead (non-gas exchanging) space and the alveolar gas composition in eight normal subjects and in three patients with pulmonary disease.

2. The results confirm the previous observations on anesthetized dogs and normal human subjects, and indicate that this dead space $(V D)$, remains constant over a wide range of tidal volumes and during a variety of experimental conditions. The average $V_{D}$ in the seven male subjects was $164 \mathrm{ml}$.

3. An attempt has been made to identify the VD measured by the iso-saturation method. This well-defined VD containing inspired gas, must be distinguished from the virtual, "physiological" VD calculated from blood gas tensions, which may vary during exercise and in pulmonary disease, due to changes in the dynamics of alveolar ventilation, and alveolar ventilation-perfusion relationships.

4. The alveolar gas compositions determined by this method were coupled with results of direct arterial blood gas analyses for the calculation of the alveolar-arterial ( $\mathrm{A}-\mathrm{a}$ ) oxygen and carbon dioxide pressure gradients. In the normal subjects, the A-a oxygen and carbon dioxide gradients averaged 6 and $0.5 \mathrm{~mm} . \mathrm{Hg}$, respectively.

5. The A-a gradients were applied to the calculation of the oxygen diffusion capacity of the lungs in the normal subjects; the $\mathrm{DLO}_{2}$, at rest, was calculated to be $22 \mathrm{ml}$. per min. per $\mathrm{mm}$. $\mathrm{Hg}$.

6. The A-a gradient and VD were similarly studied in three patients with three different types of pulmonary dysfunction. The A-a oxygen gradient and the VD were considerably increased in one subject with diffuse pulmonary granulomatosis, but were within normal limits in one patient with chronic non-obstructive emphysema, and in another patient with a single distended lung. The results of the VD measurements in the patient with diffuse pulmonary granulomatosis were used to emphasize the theoretical differences between the VD measured by the iso-saturation method and the "physiological" VD.

\section{ACKNOWLEDGMENT}

The author gratefully acknowledges the help and encouragement received from Dr. A. Cournand during the course of these studies, and the aid of Dr. P. Samet and other members of the Laboratory in the execution of many of these experiments. 


\section{REFERENCES}

1. Pappenheimer, J. R., Fishman, A. P., and Borrero, L. M., New experimental methods for determination of effective alveolar gas composition and respiratory dead space, in the anesthetized dog and in man. J. Applied Physiol., 1952, 4, 855.

2. Bateman, J. B., Alveolar air, respiratory dead space and the "ventilation index." Proc. Soc. Exper. Biol. \& Med., 1950, 73, 683.

3. Riley, R. L., Proemmel, D. D., and Franke, R. E., A direct method for determination of oxygen and carbon dioxide tensions in blood. J. Biol. Chem., 1945, 161, 621.

4. Riley, R. L., Cournand, A., and Donald, K. W., Analysis of factors affecting partial pressures of oxygen and carbon dioxide in gas and blood of the lungs: Methods. J. Applied Physiol., 1951, 4, 102.
5. Riley, R. L., and Cournand, A., Analysis of factors affecting partial pressures of oxygen and carbon dioxide in gas and blood of lungs: Theory. J. Applied Physiol., 1951, 4, 77.

6. Fowler, W. S., Lung function studies. II. The respiratory dead space. Am. J. Physiol., 1948, 154, 405.

7. DuBois, A. B., Fowler, R. C., Soffer, A., and Fenn, W. O., Alveolar $\mathrm{CO}_{2}$ measured by expiration into the rapid infrared gas analyzer. J. Applied Physiol., 1952, 4, 526.

8. Hatch, T., Cook, K. M., and Palm, P. E., Respiratory dead space. J. Applied Physiol., 1953, 5, 341.

9. Lilienthal, J. L., Jr., Riley, R. L., Proemmel, D. D., and Franke, R. E., An experimental analysis in man of the oxygen pressure gradient from alveolar air to arterial blood during rest and exercise at sea level and at altitude. Am. J. Physiol., 1946, 147, 199.

\section{ANNOUNCEMENTS OF MEETINGS}

The 46th Annual Meeting of the American Society for Clinical Investigation will be held in Atlantic City, N. J., on Monday, May 3, 1954, with headquarters at the Chalfonte-Haddon Hall. The scientific session will begin at 9 a.m. at the Steel Pier Theater.

The annual meeting of the Association of American Physicians will be held at the Chalfonte-Haddon Hall on Tuesday, May 4, and Wednesday, May 5, 1954. 